\title{
BMJ Determinants of self-reported smoking open and misclassification during pregnancy, and analysis of optimal cut-off points for urinary cotinine: a cross-sectional study
}

.

Juan J Aurrekoetxea, ${ }^{1,2,3}$ Mario Murcia, ${ }^{4,5}$ Marisa Rebagliato, ${ }^{4,5}$

María José López, ${ }^{4,6,7}$ Ane Miren Castilla, ${ }^{4,8}$ Loreto Santa-Marina, ${ }^{1,3,4}$ Mónica Guxens, ${ }^{4,9,10}$ Ana Fernández-Somoano, ${ }^{4,11}$ Mercedes Espada, ${ }^{8}$ Aitana Lertxundi, ${ }^{2,3,4}$ Adonina Tardón, ${ }^{4,11}$ Ferran Ballester ${ }^{4,5,12}$

To cite: Aurrekoetxea JJ, Murcia M, Rebagliato M, et al. Determinants of selfreported smoking and misclassification during pregnancy, and analysis of optimal cut-off points for urinary cotinine: a crosssectional study. BMJ Open 2013;3:e002034. doi:10.1136/ bmjopen-2012-002034

- Prepublication history and additional material for this paper are available online. To view these files please visit the journal online (http://dx.doi.org/10.1136/ bmjopen-2012-002034).

Received 8 September 2012 "Revised 18 December 2012 Accepted 20 December 2012

This final article is available for use under the terms of the Creative Commons Attribution Non-Commercial 2.0 Licence; see http://bmjopen.bmj.com

For numbered affiliations see end of article.

Correspondence to Dr Juan J Aurrekoetxea; jj.aurreko@gmail.com

\section{ABSTRACT}

Objectives: To estimate the prevalence and factors associated with smoking and misclassification in pregnant women from INMA (INfancia y Medio Ambiente, Environment and Childhood) project, Spain, and to assess the optimal cut-offs for urinary cotinine (UC) that best distinguish daily and occasional smokers with varying levels of second-hand smoke (SHS) exposure.

Design: We used logistic regression models to study the relationship between sociodemographic variables and self-reported smoking and misclassification (selfreported non-smokers with $U C>50 \mathrm{ng} / \mathrm{ml}$ ). Receiver operating characteristic (ROC) curves were used to calculate the optimal cut-off point for discriminating smokers. The cut-offs were also calculated after stratification among non-smokers by the number of sources of SHS exposure. The cut-off points used to discriminate smoking status were the level of UC given by Youden's index and for 50 and $100 \mathrm{ng} / \mathrm{ml}$ for daily smokers, or 25 and $50 \mathrm{ng} / \mathrm{ml}$ for occasional smokers.

Participants: At the third trimester of pregnancy, 2263 pregnant women of the INMA Project were interviewed between 2004 and 2008 and a urine sample was collected. Results: Prevalence of self-reported smokers at the third trimester of pregnancy was $18.5 \%$, and another $3.9 \%$ misreported their smoking status. Variables associated with self-reported smoking and misreporting were similar, including born in Europe, educational level and exposure to SHS. The optimal cut-off was $82 \mathrm{ng} / \mathrm{ml}$ (95\% Cl 42 to 133 ), sensitivity $95.2 \%$ and specificity $96.6 \%$. The area under the ROC curve was $0.986(95 \%$ $\mathrm{Cl} 0.982$ to 0.990$)$. The cut-offs varied according to the SHS exposure level being 42 ( $95 \% \mathrm{Cl} 27$ to 57 ), 82 (95\% Cl 46 to 136) and $106 \mathrm{ng} / \mathrm{ml}(95 \% \mathrm{Cl} 58$ to 227) for not being SHS exposed, exposed to one, and to two or more sources of SHS, respectively. The optimal cut-off for discriminating occasional smokers from non-smokers was $27 \mathrm{ng} / \mathrm{ml}(95 \% \mathrm{Cl} 11$ to 43$)$.

Conclusions: Prevalence of smoking during pregnancy in Spain remains high. UC is a reliable biomarker for classifying pregnant women according to their smoking status. However, cut-offs would differ based on baseline exposure to SHS.

\section{ARTICLE SUMMARY}

Article focus

- There is no current consensus regarding the cut-off point for urinary cotinine in pregnant women able to discriminate regular or occasional smokers from non-smokers.

- These cut-offs would also differ according to baseline exposure to second-hand smoke (SHS).

- This study assesses the maternal factors influencing both self-reported and misclassification of smoking and evaluate the optimal cut-off point for urinary cotinine that best distinguishes smokers from non-smokers, according to the frequency of smoking and SHS exposure.

Key messages

- The prevalence of both smoking $(18.5 \%)$ and SHS exposure (45.9\%) was high in a populationbased sample of pregnant women in Spain.

- Factors associated with self-reported smoking and misreporting were similar, including lower level of education and living in a smoking environment, which highlights the need of reinforcing the preventive interventions and policies.

- The optimal cut-off point to discriminate smokers from non-smokers varied according to the frequency of smoking (occasional or daily smokers) and SHS exposure levels.

- This study highlights the importance of SHS exposure for selecting reference cut-offs to discriminate smoking status, especially in high-SHSexposed populations.

Strengths and limitations of this study

- This study has the ability to assess the role of baseline exposures to SHS in the estimate of cut-offs, given the detailed information collected on SHS exposure and its elevated prevalence.

- This study uses population-based samples of pregnant women from the INfancia y Medio Ambiente birth cohort, which might not be fully representative of all pregnant women in the study areas. 


\section{INTRODUCTION}

Risks for mother and fetus have been widely related to smoking during pregnancy. ${ }^{1}$ Several studies have indicated that pregnant women tend to under-report their consumption of tobacco, ${ }^{2-8}$ owing to social pressure ${ }^{9}$ or to avoid criticism from health professionals. ${ }^{3}$ Indeed, it is known to be a higher rate of misreporting of smoking among the groups in which it is not considered as acceptable, such as pregnant women and patients with smoking-related diseases. ${ }^{9}$

Cotinine is the main metabolite of nicotine and the biomarker of choice for distinguishing smokers from non-smokers and for assessing exposure to second-hand smoke (SHS). ${ }^{10}$ Women's clearance of cotinine is faster during pregnancy ${ }^{11}$ and their plasma half-life is a little less than 9 h. ${ }^{12}$ For this reason, urinary cotinine (UC) tests may give false negatives in pregnant women who have not recently smoked.

There is no current consensus regarding the cut-off point for UC in pregnant women. Several thresholds have been proposed, with $50 \mathrm{ng} / \mathrm{ml}$ being the most widely used..$^{13-16}$ On the other hand, Higgins et al ${ }^{17}$ proposed $25 \mathrm{ng} / \mathrm{ml}$ as the cut-off point, while Gorber et at underlined the need to decide on a suitable threshold for pregnant women in particular, for whom the sensitivity of the test may be different, and also suggested that a new cut-off point should be established for occasional smokers. Spierto et $a l^{18}$ found $79 \mathrm{ng} / \mathrm{ml}$ as the cut-off between non-smoking and smoking pregnant women.

The aims of our study were (1) to assess the prevalence of self-reported smoking and the UC levels in a cohort of pregnant women; (2) to assess the prevalence of misclassification of maternal smoking status according to the most widely accepted cut-off point in the literature of $50 \mathrm{ng} / \mathrm{ml}$, and to study maternal factors associated with both self-reported and misclassification of maternal smoking and (3) to identify the optimal cut-off point for UC that best distinguishes smokers from nonsmokers in our study sample, according to the frequency of smoking (occasional or daily smokers) and SHS exposure.

\section{METHODS}

\section{Study population}

The INMA (INfancia y Medio Ambiente, Environment and Childhood) project is a Spanish multicentre prospective birth cohort study which aims to evaluate the impact of exposure to the most prevalent environmental pollutants, and the role of diet on fetal and infant growth, health and development. ${ }^{19}$ From eligible pregnant women recruited between 2003 and 2008, 56\% agreed to participate. The inclusion criteria were at least 16 years of age, singleton pregnancy, enrolment at 10-13 weeks of gestation, no assisted conception, delivery scheduled at the reference hospital and no communication handicap. There was no upper age limit for becoming a member of the cohort. Of the 2644 women who agreed to participate in the study, $119(4.5 \%)$ were lost (59 miscarriages, 8 fetal death, 47 withdrew and 5 lost to follow-up). Around week 32 of their pregnancy, 2263 of the 2525 remaining women completed, between 2004 and 2008, a questionnaire on smoking and other variables and provided urine samples for determination of UC (figure 1). The hospital ethics committee of each centre approved the research protocol, and all pregnant women gave written informed consent before inclusion at the first trimester of pregnancy.

\section{Information concerning smoking}

Questionnaire on tobacco consumption included smoking history, patterns of consumption (occasional or regular) and exposure to SHS. We considered the women who, at this interview, reported smoking occasionally or daily to be smokers, regardless of their UC levels. Women who had UC levels higher than the widely used level of $50 \mathrm{ng} / \mathrm{ml}$ to distinguish smokers from non-smokers, ${ }^{13-16}$ but who did not report smoking, were classed as misclassified. It was considered that the participants were exposed to SHS when they reported exposure at least twice a week in any of the following environments: at work, at home or in leisure time outside the home (eg, bars/restaurants or other homes). We analysed whether women had any passive exposure to tobacco smoke (yes or no) and also the number of exposure sources, between 0 and 3 ,
Figure 1 Flow chart of the INfancia y Medio Ambiente birth cohort in relation to smoking and urinary cotinine quantification.

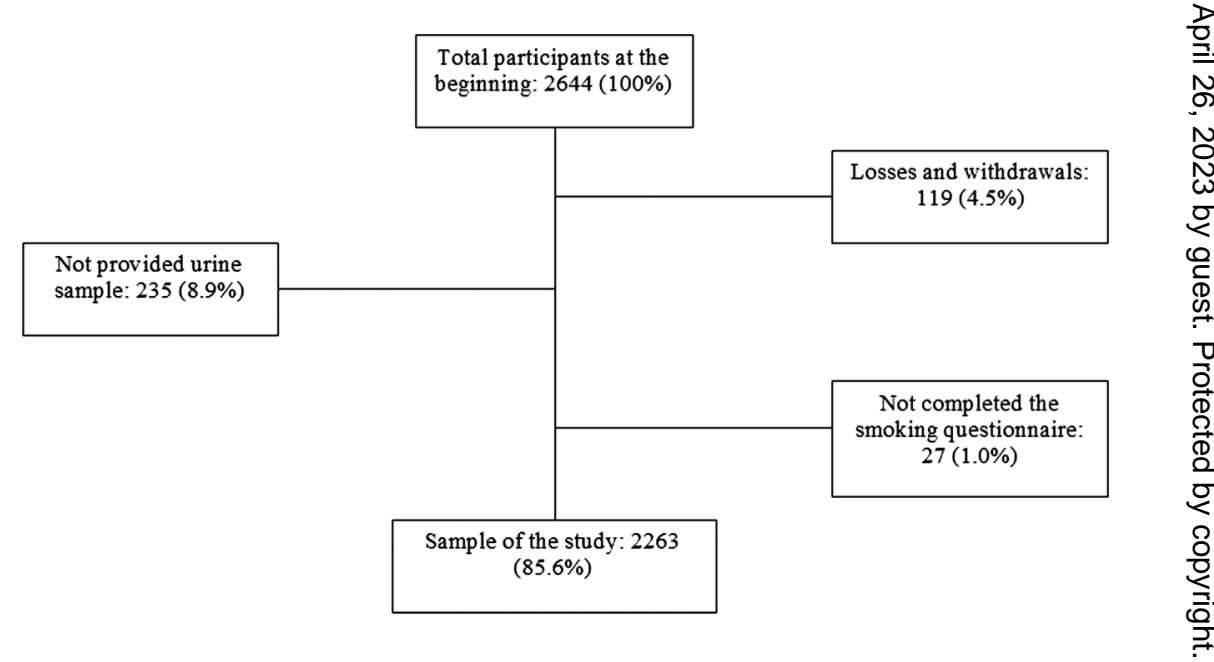


according to the reported places of exposure: at work, at home and/or elsewhere in leisure time.

\section{Urinary cotinine}

The urine samples were collected in the same interview in the morning during the third trimester of pregnancy. Urine was collected in $100 \mathrm{ml}$ polyethylene containers and stored at $-20^{\circ} \mathrm{C}$. One aliquot of the sample from each of the participants was sent to the Public Health Laboratory of Bilbao (Spain) to be analysed. All urine samples were stored for a minimum of 1 year and a maximum of 5 years before analysis. The analysis of the UC was performed by competitive enzyme immunoassay (EIA) using commercial EIA microplate test kits (OraSure Technologies, Inc, Bio-Rad) for determining salivary cotinine adapted for urine samples using urine controls (0, 2.5, 10 and $50 \mathrm{ng} / \mathrm{ml}$, Bio-Rad). Samples with UC levels above $50 \mathrm{ng} / \mathrm{ml}$ were diluted. Before testing the urine samples, the method was validated; a certified reference material was used (EPA/NIST Reference Material 8444) to evaluate the repeatability and reproducibility. The quantification limit was $4.0 \mathrm{ng} / \mathrm{ml}$, the coefficient of repeatability $7 \%$ and the reproducibility $10 \%$.

\section{Other variables}

The women were interviewed twice during pregnancy (in the first and third trimesters of gestation) to obtain information about their sociodemographic characteristics and lifestyle variables. Social status of the women (or her partner, if she had never worked outside home) was defined using Spanish adaptation of the British classification system. ${ }^{20}$

\section{Statistical analysis}

The $\chi^{2}$ test was used to test hypotheses for categorical variables, whereas differences in the distribution of $\mathrm{UC}$, according to categorical covariates, were evaluated using the Mann-Whitney $\mathrm{U}$ and the Kruskal Wallis tests. In order to identify the variables independently associated with being either a smoker, a misclassified or both, logistic regression models were built including geographical area and the variables related with the outcome at $\mathrm{p}<0.10$ in the univariate analysis, and sequentially excluding those variables not related at $\mathrm{p}<0.10$ in the adjusted model using the likelihood ratio test. For comparability purposes, variables remaining at $\mathrm{p}<0.10$ in any of the models were entered in all the models. For ordinal categorical variables, the $\mathrm{p}$ for a linear trend was also calculated.

We used the non-parametric receiver operating characteristic (ROC) curve to analyse the relationship between the sensitivity (probability of a positive test among smokers) and false-positive (probability of a positive test among non-smokers, 1-specificity) cases for various different cut-off points that dichotomise UC to distinguish smokers from non-smokers, using self-reported cigarettesmoking status as the reference value. Overall accuracy was evaluated by means of the area under the curve
(AUC) (showing the ability of the urinary cotinine to correctly classify smoking status with varying cut-off points. ${ }^{21}$ The optimal cut-off point for UC to discriminate smokers from non-smokers was the value (c) associated with Youden's index $(\mathrm{J})$, defined by: $\mathrm{J}=$ maximum $\{$ sensitivity (c)+specificity(c) -1$\} .^{22}$ This value is 'optimal' in the sense that it maximises the overall rate of correct classification in the absence of a loss function (ie, giving the same weight to errors of sensitivity and specificity). Since the shape of the distribution of the estimator of the optimal cut-off point was unknown, we used the percentile bootstrap method, with 2000 resampling simulations, to establish $95 \%$ CI, with the aid of the 'boot' package of R. ${ }^{23}$ Additionally, the data were analysed for the most widely used cut-off points, namely 50 and $100 \mathrm{ng} / \mathrm{ml}$, or 25 and $50 \mathrm{ng} / \mathrm{ml}$ when analyses were restricted to occasional smokers. The cut-off points were also calculated after stratification among non-smokers for SHS exposure in three groups: 798 women that referred not exposed to SHS, 735 exposed to one source of SHS and 303 exposed to more than one source. Additional sensitivity analyses were conducted (see online supplementary table), the first one excluding 1047 pregnant women non-smokers who referred SHS exposure, the second one excluding 317 self-reported non-smokers who claimed to have stopped smoking during pregnancy, since this group is more likely to misreport their smoking status, and the last one excluding 35 women who declared that they did not smoke but had implausible UC levels in non smokers (>500 ng/ $\mathrm{ml}$ ). Assuming $\alpha=0.05,95 \%$ CI were calculated for ORs, cut-off points and area under the ROC curve. All statistical tests were two-sided. Statistical analysis was carried out using SPSS (V.17.0) and R (2.11.1) statistical software.

\section{RESULTS}

\section{Study setting and characteristics of the sample}

Overall, $61.2 \%$ of women reported to have smoked at least once in their life, whereas $32.4 \%$ were occasional or regular smokers when they became pregnant, falling to $19.7 \%$ at the first trimester and $18.5 \%$ at the third trimester of their pregnancy (table 1 ).

\section{Smoking and SHS exposure}

The median UC level in women who did not refer to smoke and were not exposed to SHS was below the quantification level of $4.0 \mathrm{ng} / \mathrm{ml}$, whereas in non-smokers exposed to SHS, it was $7.6 \mathrm{ng} / \mathrm{ml}$. Among all smokers, the UC median level was $1744.3 \mathrm{ng} / \mathrm{ml}$ (table 2). Occasional smokers had a median level of $260.7 \mathrm{ng} / \mathrm{ml}$. Among daily smokers, statistically significant differences were observed between UC concentration and the number of cigarettes smoked per day $(\mathrm{p}<0.001)$, showing a clear dose-response pattern (not statistically tested). In the same way, in nonsmokers, there were statistically significant differences between UC levels and the number of sources of exposure 
Table 1 Description of the sample and variables of interest

\begin{tabular}{|c|c|c|}
\hline & $\mathbf{N}^{*}$ & $\%$ \\
\hline \multicolumn{3}{|l|}{ Cohort } \\
\hline Asturias & 416 & 18.4 \\
\hline Gipuzkoa & 545 & 24.1 \\
\hline Sabadell & 591 & 26.1 \\
\hline Valencia & 711 & 31.4 \\
\hline \multicolumn{3}{|l|}{ Age } \\
\hline$\leq 24$ & 154 & 6.8 \\
\hline 25-29 & 717 & 31.7 \\
\hline $30-34$ & 973 & 43.0 \\
\hline$\geq 35$ & 418 & 18.5 \\
\hline \multicolumn{3}{|l|}{ Social class } \\
\hline I-II (more affluent) & 492 & 21.8 \\
\hline III & 584 & 25.8 \\
\hline IV-V (less affluent) & 1186 & 52.4 \\
\hline \multicolumn{3}{|l|}{ Level of education } \\
\hline Primary or no education & 547 & 24.2 \\
\hline Secondary & 936 & 41.4 \\
\hline University & 776 & 34.4 \\
\hline \multicolumn{3}{|l|}{ BMI (pre-pregnancy) } \\
\hline$<18.5$ & 100 & 4.4 \\
\hline $18.5-25$ & 1568 & 69.3 \\
\hline $25-30$ & 420 & 18.6 \\
\hline$\geq 30$ & 175 & 7.7 \\
\hline Previous parity & 957 & 43.1 \\
\hline Birth in Europe & 2130 & 94.3 \\
\hline \multicolumn{3}{|c|}{ Reported having smoked in their life } \\
\hline No & 879 & 38.8 \\
\hline Occasional & 146 & 6.5 \\
\hline Regular & 1238 & 54.7 \\
\hline \multicolumn{3}{|c|}{ Reported smoking at the start of pregnancy } \\
\hline No & 1529 & 67.6 \\
\hline Occasional & 28 & 1.2 \\
\hline Regular & 706 & 31.2 \\
\hline \multicolumn{3}{|c|}{$\begin{array}{l}\text { Reported smoking at the first trimester of } \\
\text { pregnancy }\end{array}$} \\
\hline No & 1813 & 80.3 \\
\hline Occasional & 35 & 1.6 \\
\hline Regular & 410 & 18.2 \\
\hline \multicolumn{3}{|c|}{$\begin{array}{l}\text { Reported smoking at the third trimester of } \\
\text { pregnancy }\end{array}$} \\
\hline No & 1845 & 81.5 \\
\hline Occasional & 37 & 1.6 \\
\hline Regular & 381 & 16.8 \\
\hline \multicolumn{3}{|l|}{ Year of urine sampling } \\
\hline 2004 & 321 & 14.2 \\
\hline 2005 & 857 & 37.9 \\
\hline 2006 & 466 & 20.6 \\
\hline 2007 & 470 & 20.8 \\
\hline 2004 & 149 & 6.6 \\
\hline \multicolumn{3}{|c|}{$\begin{array}{l}\text { Cigarettes/day at the third trimester of } \\
\text { pregnancy }\end{array}$} \\
\hline 0 & 1845 & 81.5 \\
\hline Occasional & 37 & 1.6 \\
\hline $1-4$ & 149 & 6.6 \\
\hline $5-9$ & 141 & 6.2 \\
\hline$\geq 10$ & 91 & 4.0 \\
\hline
\end{tabular}

Exposed to SHS in non-smoking woment:
Table 1 Continued

\begin{tabular}{lrr}
\hline & $\mathbf{N}^{*}$ & $\%$ \\
\hline At home (partner or others) & 479 & 26.0 \\
At work & 186 & 10.1 \\
Elsewhere in leisure time $¥$ & 715 & 38.8 \\
Number of sources of exposure to SHS§ & & \\
0 & 798 & 43.5 \\
1 & 735 & 40.0 \\
2 & 271 & 14.8 \\
3 & 32 & 1.7 \\
Cotinine (ng/ml) all the women & & \\
$<50$ & 1773 & 78.3 \\
$50-99$ & 31 & 1.4 \\
$100-199$ & 19 & 0.8 \\
$200-499$ & 52 & 2.3 \\
$500-999$ & 70 & 3.1 \\
$\geq 1000$ & 318 & 14.1 \\
\hline
\end{tabular}

${ }^{*}$ The numbers and rates that do not match the total are due to missing data.

†Percentages calculated including non-exposed women.

†Other homes or public places, for example, pubs or restaurants. $\S$ Work, home and elsewhere in leisure time among non-smokers.

$\mathrm{BMI}$, body mass index; SHS, second-hand smoke.

to SHS, which are, work, home and elsewhere in leisure time $(\mathrm{p}<0.001)$, with a progressive dose-response pattern (not tested, neither). Figure 2 shows the different distribution patterns of UC among non-smokers, exposed or not to SHS, and occasional and daily smokers.

\section{Self-reported smoking and misclassification}

Among the 2263 women studied, 1755 (77.6\%) reported that they did not smoke and had UC levels below $50 \mathrm{ng} / \mathrm{ml}$

Table 2 Active smoking and exposure to SHS in pregnant women in the INfancia y Medio Ambiente cohort. Median levels of urinary cotinine $(\mathrm{ng} / \mathrm{ml})$ at the third trimester of pregnancy

\begin{tabular}{lrrc}
\hline & N & \multicolumn{1}{c}{$\%$} & Urinary cotinine \\
\hline Total & 2263 & 100 & 7.4 \\
Non-smokers $†$ & 1845 & 81.5 & 4.4 \\
No SHS exposure & 798 & 35.3 & $<4$ \\
SHS exposure & 1038 & 45.9 & 7.6 \\
$\quad$ 1 source $\$$ $§$ & 735 & 32.5 & 5.8 \\
2 sources & 271 & 12.0 & 11.7 \\
3 sources & 32 & 1.4 & 16.9 \\
Smokers $§$ & 418 & 18.5 & 1744.3 \\
Occasional & 37 & 1.6 & 260.7 \\
1-2 cigarettes/day & 76 & 3.4 & 1036.4 \\
3-4 cigarettes/day & 73 & 3.2 & 1330.7 \\
5-9 cigarettes/day & 141 & 6.2 & 1848.5 \\
$\geq 10$ cigarettes/day & 91 & 4.0 & 3033.0 \\
\hline
\end{tabular}

SHS, second-hand smoke.

*Median level of urinary cotinine $\mathrm{ng} / \mathrm{ml}$.

†Exposed and not exposed to SHS; Mann-Whitney test: $p<0.001$ for smoking and urinary cotinine.

¥Sources of exposure to SHS at work/at home/in leisure time outside the home.

§Kruskal Wallis test $p<0.001$. 


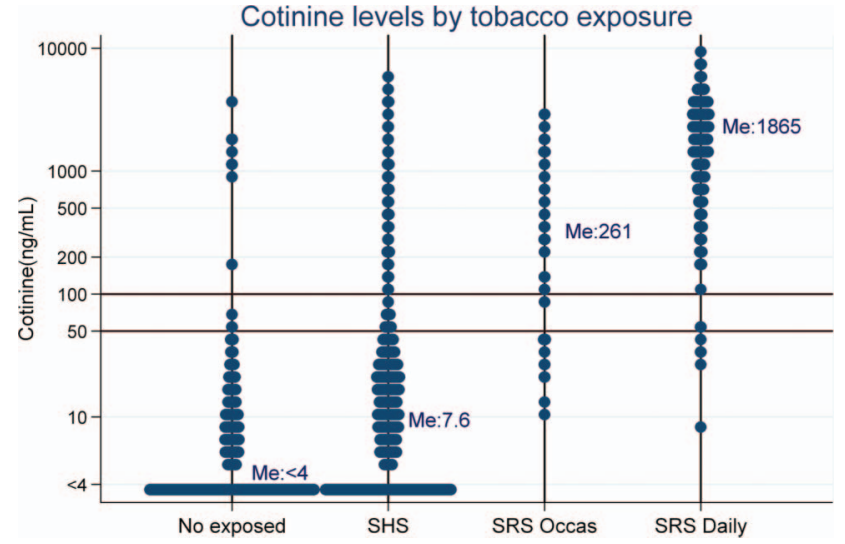

Figure 2 Distribution of urinary cotinine $(\mathrm{ng} / \mathrm{ml})$ according to active or passive tobacco exposure in pregnant women from the INfancia y Medio Ambiente cohort. Me, median; SHS, second-hand smoking; SRS Occas, self-reported smoking, occasional; SRS Daily, self reported smoking, daily.

(true negative). A further $18(0.8 \%)$ also had UG levels under $50 \mathrm{ng} / \mathrm{ml}$ despite claiming to smoke, though 13 of these claimed to be occasional smokers. On the other hand, 90 women $(3.9 \%)$ reported that they did not smoke but were found to have UC levels above $50 \mathrm{ng} / \mathrm{ml}$ and were considered as misclassified, and finally, 400 women (17.7\%) were true positive. Table 3 shows the ORs of the variables associated with smoking and misclassification, before and after adjusting. In the adjusted model, the risks of smoking and misclassification were associated with low educational level, country of birth and exposure to SHS. Age was related only to misclassification risk. In regard to smoking history, only smoking at the beginning of pregnancy was associated with misclassification. The year of urine sampling and the social class were statistically associated only in the unadjusted analysis. Adding women misclassified to self-reported smokers, the pattern of the association found with self-reported smoking did not vary.

\section{Cut-off points of UC for smoking}

Optimal cut-off points for distinguishing non-smokers from smokers (daily and occasional), calculated by Youden's index, was $82 \mathrm{ng} / \mathrm{ml}$, with a sensitivity of $95.2 \%$, specificity of $96.6 \%$ and AUC of 0.986 (95\% CI 0.982 to 0.990 ) (table 4 ). Sensitivity and specificity for the cut-off points of 50 and $100 \mathrm{ng} / \mathrm{ml}$ were quite close to that of $82 \mathrm{ng} / \mathrm{ml}$. Results of sensitivity analysis are shown in the online supplementary table. The exclusion of cases more prone to bias (317 women who declare to have stopped smoking during pregnancy or 35 selfreported non-smokers with implausible high UC levels) did not improve substantially the validation parameters of the tests.

Youden's index and AUC for daily smoking were higher, with a cut-off point of $115 \mathrm{ng} / \mathrm{ml}$. Occasional smoking was analysed by excluding from the analysis the 381 women who admitted that they smoked regularly at the third trimester of pregnancy. The optimal cut-off point for discriminating occasional smokers from nonsmokers was $27 \mathrm{ng} / \mathrm{ml}$ (95\% CI 11 to 43), with a sensitivity and specificity of $89.2 \%$ and $89.7 \%$, respectively. The exclusion of women who declared having quit smoking during pregnancy improved the specificity to $91.8 \%$, but it did not almost change Youden's index or the sensitivity. Excluding non-SHS-exposed among non-smokers, the optimal cut-off point was $19 \mathrm{ng} / \mathrm{ml}$ (95\% CI 11 to 33 ), improving the specificity to $93.7 \%$ and the positive predictive value (probability of smoking status being a positive test) to $41.2 \%$. Nevertheless, these low positivepredictive values are a consequence, above all, of the low prevalence of occasional smoking in this sample.

Women not exposed to SHS compared with all smokers, daily or occasional, had a lower cut-off point of $42 \mathrm{ng} / \mathrm{ml}$ (95\% CI 27 to 57), whereas, for those exposed to one or to two or more sources of SHS, the cut-off points were 82 (95\% CI 55 to 136$)$ and $106 \mathrm{ng} / \mathrm{ml}(95 \%$ CI 79 to 201), respectively.

\section{DISCUSSION}

\section{Main findings in relation to the literature}

The prevalence of smoking in pregnant women at the third trimester was $18.5 \%$. In this later stage, the prevalence of active smoking increased up to $22.5 \%$, if women who did not report smoking but had UC levels above $50 \mathrm{ng} / \mathrm{ml}$ were reclassified as smokers, assuming that false-positives were due to maternal misreporting of smoking status. Prevalence of self-reported smokers and misclassified in our study is close to the ones referred by Kendrick et $a t^{6}$ and Lindqvist $e t a l^{7}$ and the smoking rate and UC levels are lower than that showed by Pickett et $a l^{15}$ Our study had, nevertheless, a lower rate of smoking misreporting than other studies. ${ }^{2-8}$

There was a clear relationship between $\mathrm{UC}$ and smoking dose among smokers, and with the number of sources of exposure to SHS among non-smokers. Specifically, those who smoked 10 or more cigarettes per day had median UC levels of $3033 \mathrm{ng} / \mathrm{ml}$, whereas the levels were $260 \mathrm{ng} / \mathrm{ml}$ for occasional smokers and less than $17 \mathrm{ng} / \mathrm{ml}$ for non-smokers, increasing with the number of sources of exposure to SHS. These data reinforce the validity of $\mathrm{UC}$ also as an indicator of exposure to SHS. $^{10}$

England $e t a l^{13}$ indicated that few studies have identified differences between misclassified and self-reported smokers and the way in which this would affect epidemiological studies. Our study shows similar patterns of association, and both self-reported smoking and misclassification were strongly associated with various predictive variables. In particular, we found a higher risk of smoking and misclassification among women with low education level. These results are consistent with those reported by other authors. ${ }^{6} 1424$ We also found a higher risk of smoking and misclassification in women from Europe and women exposed to SHS in different places. Women younger than 24 years had an increased risk of 


\begin{tabular}{|c|c|c|c|c|c|c|c|c|c|c|c|c|c|}
\hline & \multicolumn{7}{|c|}{ Unadjusted analysis } & \multicolumn{6}{|c|}{ Adjusted analysis* } \\
\hline & \multirow{2}{*}{$\frac{\text { Non-smokers } †}{\mathrm{~N}}$} & \multicolumn{3}{|c|}{$\begin{array}{l}\text { Self-reported } \\
\text { smokers } ¥\end{array}$} & \multicolumn{3}{|c|}{ Misclassification§ } & \multicolumn{2}{|c|}{$\begin{array}{l}\text { Self-reported } \\
\text { smokers } \neq\end{array}$} & \multicolumn{2}{|c|}{ Misclassification§ } & \multicolumn{2}{|c|}{ Bothๆ } \\
\hline & & $\bar{N}$ & OR & $95 \% \mathrm{Cl}$ & $\overline{\mathbf{N}}$ & OR & $95 \% \mathrm{Cl}$ & $\overline{\text { OR }}$ & $95 \% \mathrm{Cl}$ & $\overline{\text { OR }}$ & $95 \% \mathrm{Cl}$ & $\overline{\text { OR }}$ & $95 \% \mathrm{Cl}$ \\
\hline Total & 1755 & 418 & - & & 90 & - & & - & & - & & - & \\
\hline \multicolumn{14}{|l|}{ Cohort } \\
\hline Asturias & 326 & 75 & 1 & - & 15 & 1 & - & 1 & - & 1 & - & 1 & - \\
\hline Gipuzkoa & 467 & 65 & 0.60 & 0.42 to 0.88 & 13 & 0.60 & 0.27 to 1.36 & 0.77 & 0.52 to 1.15 & 0.63 & 0.28 to 1.42 & 0.75 & 0.52 to 1.09 \\
\hline Sabadell & 466 & 99 & 0.92 & 0.66 to 1.29 & 26 & 1.21 & 0.61 to 2.44 & 0.68 & 0.47 to 0.99 & 0.81 & 0.40 to 1.64 & 0.72 & 0.51 to 1.02 \\
\hline Valencia & 496 & 179 & 1.57 & 1.15 to 2.15 & 36 & 1.58 & 0.82 to 3.07 & 0.94 & 0.67 to 1.33 & 0.84 & 0.43 to 1.66 & 0.95 & 0.69 to 1.31 \\
\hline \multicolumn{14}{|l|}{ Age } \\
\hline$\leq 24$ & 93 & 43 & 1 & - & 18 & 1 & - & 1 & - & 1 & - & 1 & \\
\hline $25-29$ & 537 & 152 & 0.62 & 0.40 to 0.94 & 28 & 0.27 & 0.14 to 0.53 & 0.87 & 0.55 to 1.38 & 0.36 & 0.18 to 0.73 & 0.73 & 0.49 to 1.11 \\
\hline $30-34$ & 792 & 153 & 0.42 & 0.27 to 0.64 & 28 & 0.18 & 0.09 to 0.36 & 0.75 & 0.48 to 1.19 & 0.26 & 0.13 to 0.54 & 0.61 & 0.41 to 0.92 \\
\hline$\geq 35$ & 332 & 70 & 0.46 & $\begin{array}{l}0.29 \text { to } 0.73 \\
\left({ }^{\star *} p<0.001\right)\end{array}$ & 16 & 0.25 & $\begin{array}{l}0.12 \text { to } 0.54 \\
\left({ }^{* *} p=0.001\right)\end{array}$ & 0.90 & 0.54 to 1.49 & 0.46 & 0.21 to 1.04 & 0.76 & 0.48 to 1.19 \\
\hline \multicolumn{14}{|l|}{ Country of birth } \\
\hline In Europe & 1637 & 410 & 1 & - & 83 & 1 & - & 1 & - & 1 & & 1 & - \\
\hline Outside Europe & 114 & 8 & 0.28 & 0.13 to 0.60 & 7 & 1.21 & 0.50 to 2.79 & 0.25 & 0.12 to 0.54 & 1.11 & 0.46 to 2.65 & 0.39 & 0.21 to 0.69 \\
\hline \multicolumn{14}{|l|}{ Level of education } \\
\hline University & 695 & 59 & 1 & - & 22 & 1 & - & 1 & - & 1 & - & 1 & - \\
\hline Secondary & 703 & 192 & 3.22 & 2.36 to 4.39 & 41 & 1.84 & 1.09 to 3.17 & 2.37 & 1.70 to 3.29 & 1.17 & 0.66 to 2.08 & 2.08 & 1.55 to 2.78 \\
\hline Primary or less & 355 & 165 & 5.47 & $\begin{array}{l}3.96 \text { to } 7.57 \\
\left(p^{\star *}<0.001\right)\end{array}$ & 27 & 2.40 & $\begin{array}{l}1.34 \text { to } 4.32 \\
\left(p^{\star *}=0.002\right)\end{array}$ & 3.30 & 2.31 to 4.70 & 1.02 & 0.53 to 1.97 & 2.72 & 1.97 to 3.74 \\
\hline \multicolumn{14}{|l|}{ Social class } \\
\hline I+II (highest) & 438 & 41 & 1 & - & 13 & 1 & - & - & & - & & - & \\
\hline III & 469 & 96 & 2.19 & 1.48 to 3.22 & 19 & 1.36 & 0.67 to 2.80 & - & & - & & - & \\
\hline IV+V (lowest) & 847 & 281 & 3.54 & $\begin{array}{l}2.50 \text { to } 5.02 \\
\left(p^{\star *}<0.001\right)\end{array}$ & 58 & 2.31 & $\begin{array}{l}1.25 \text { to } 4.26 \\
\left(p^{\star *}=0.002\right)\end{array}$ & - & & - & & - & \\
\hline \multicolumn{14}{|c|}{ Year of urine sampling } \\
\hline 2004 & 224 & 78 & 1 & - & 19 & 1 & - & - & & - & & - & \\
\hline 2005 & 642 & 179 & 0.80 & 0.59 to 1.09 & 36 & 0.66 & 0.37 to 1.18 & - & & - & & - & \\
\hline 2006 & 362 & 83 & 0.66 & 0.46 to 0.94 & 21 & 0.68 & 0.36 to 1.30 & - & & - & & - & \\
\hline 2007 & 399 & 58 & 0.42 & 0.29 to 0.61 & 13 & 0.38 & 0.19 to 0.79 & - & & - & & - & \\
\hline 2008 & 128 & 20 & 0.45 & $\begin{array}{l}0.26 \text { to } 0.77 \\
\left(p^{\star *}<0.001\right)\end{array}$ & 1 & 0.09 & $\begin{array}{l}0.01 \text { to } 0.70 \\
\left(\mathrm{p}^{\star *}=0.001\right)\end{array}$ & - & & - & & - & \\
\hline \multicolumn{14}{|c|}{ Exposure to SHS at home } \\
\hline No & 1328 & 144 & 1 & - & 34 & 1 & - & 1 & - & 1 & - & 1 & - \\
\hline Yes & 423 & 274 & 5.97 & 4.75 to 7.51 & 56 & 5.17 & 3.33 to 8.03 & 4.41 & 3.44 to 5.64 & 3.26 & 2.03 to 5.25 & 4.39 & 3.49 to 5.51 \\
\hline \multicolumn{14}{|c|}{ Exposure to SHS at work } \\
\hline No & 1582 & 343 & 1 & - & 76 & 1 & - & 1 & - & 1 & & 1 & - \\
\hline Yes & 172 & 74 & 1.98 & 1.48 to 2.67 & 14 & 1.69 & 0.94 to 3.06 & 1.55 & 1.11 to 2.17 & 1.37 & 0.72 to 2.59 & 1.57 & 1.14 to 2.15 \\
\hline
\end{tabular}




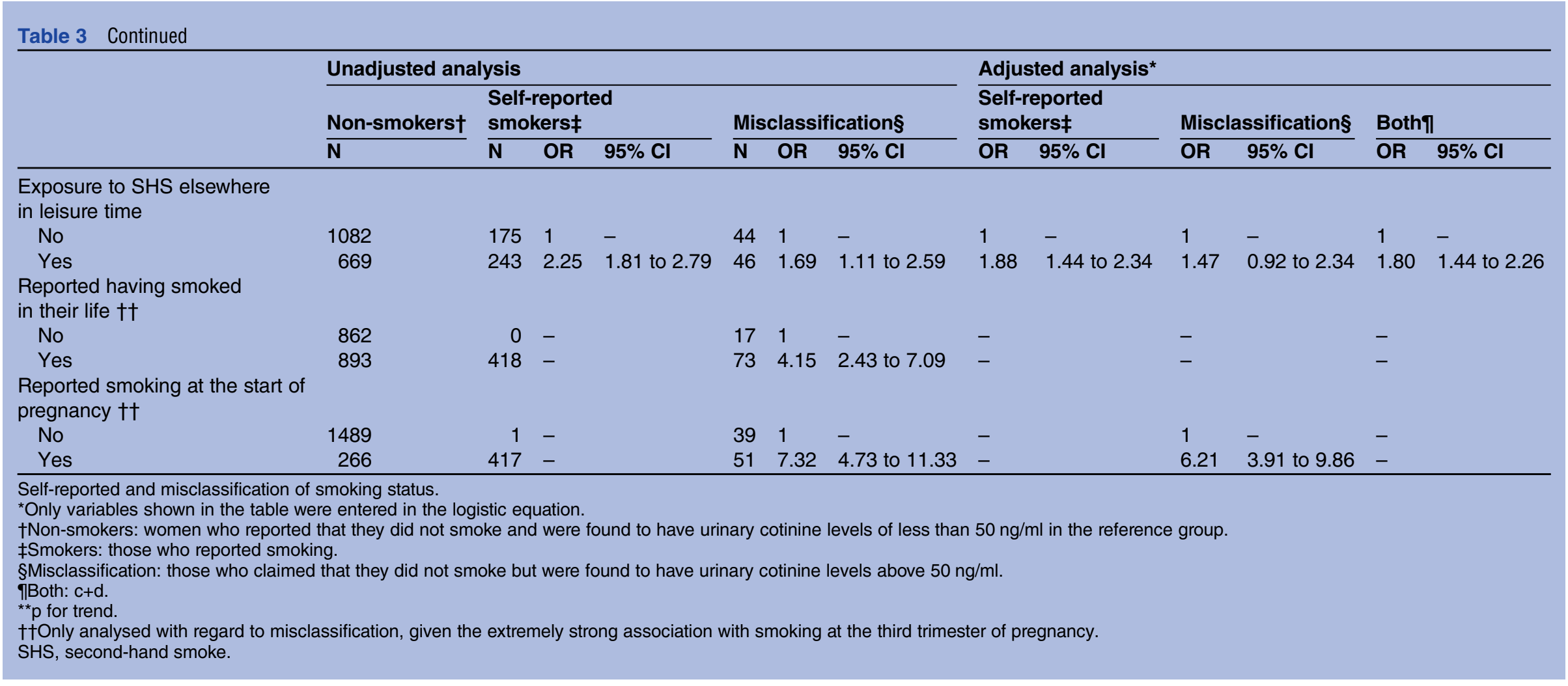


Table 4 Parameters for assessing the optimal cut-off point for urinary cotinine $(\mathrm{ng} / \mathrm{ml})$ obtained by Youden's index, as well as the levels of 25,50 and $100 \mathrm{ng} / \mathrm{ml}$, for classifying pregnant women as regular or occasional smokers

\begin{tabular}{|c|c|c|c|c|c|c|}
\hline Youden's index* & Cut-off point $(95 \% \mathrm{Cl}) \dagger$ & Sensitivity & Specificity & Positive PV¥ & Negative PV & $\begin{array}{l}\text { AUC of the ROC } \\
(95 \% \mathrm{Cl}) \S\end{array}$ \\
\hline \multicolumn{7}{|c|}{ Regular and occasional smokers: 1845 non-smokers, 418 smokers } \\
\hline- & 50 & 0.957 & 0.951 & 0.816 & 0.990 & \multirow{3}{*}{$0.986(0.982$ to 0.990$)$} \\
\hline- & 100 & 0.950 & 0.966 & 0.865 & 0.988 & \\
\hline 0.918 & $82(42$ to 136$)$ & 0.952 & 0.966 & 0.863 & 0.989 & \\
\hline \multicolumn{7}{|c|}{ Results stratified by frequency of smoking } \\
\hline \multicolumn{7}{|c|}{ Occasional smokers: 1845 non-smokers, 37 smokers } \\
\hline- & 25 & 0.892 & 0.870 & 0.121 & 0.998 & \multirow{3}{*}{0.947 (0.923 to 0.970$)$} \\
\hline- & 50 & 0.649 & 0.951 & 0.211 & 0.993 & \\
\hline 0.772 & 27 (11 to 43$)$ & 0.892 & 0.880 & 0.130 & 0.998 & \\
\hline \multicolumn{7}{|c|}{ Daily smokers: 1845 non-smokers, 381 smokers } \\
\hline- & 50 & 0.987 & 0.951 & 0.807 & 0.997 & \multirow{3}{*}{$0.990(0.986$ to 0.994$)$} \\
\hline- & 100 & 0.982 & 0.966 & 0.858 & 0.996 & \\
\hline 0.949 & $115(57$ to 189$)$ & 0.982 & 0.967 & 0.862 & 0.996 & \\
\hline \multicolumn{7}{|c|}{ Results stratified by SHS exposure among non-smokers } \\
\hline \multicolumn{7}{|c|}{ Non-exposed to SHS: 798 non-smokers, 418 active smokers } \\
\hline- & 50 & 0.957 & 0.987 & 0.976 & 0.978 & \multirow{3}{*}{$0.994(0.990$ to 0.998$)$} \\
\hline- & 100 & 0.950 & 0.990 & 0.980 & 0.974 & \\
\hline 0.954 & $42(27$ to 57$)$ & 0.971 & 0.982 & 0.967 & 0.985 & \\
\hline \multicolumn{7}{|c|}{ Exposed to SHS (1 source $\left.{ }^{\star \star}\right): 735$ non-smokers, 418 active smokers } \\
\hline- & 50 & 0.957 & 0.935 & 0.893 & 0.974 & \multirow{3}{*}{0.981 (0.974 to 0.989$)$} \\
\hline- & 100 & 0.950 & 0.958 & 0.928 & 0.971 & \\
\hline 0.910 & $82(46$ to 136$)$ & 0.952 & 0.958 & 0.928 & 0.972 & \\
\hline \multicolumn{7}{|c|}{ Exposed to SHS (2-3 sources $\left.{ }^{\star *}\right): 303$ non-smokers, 418 active smokers } \\
\hline- & 50 & 0.957 & 0.894 & 0.926 & 0.938 & \multirow{3}{*}{0.977 (0.966 to 0.987$)$} \\
\hline- & 100 & 0.950 & 0.924 & 0.945 & 0.930 & \\
\hline 0.877 & 106 (58 to 227) & 0.950 & 0.927 & 0.947 & 0.930 & \\
\hline
\end{tabular}

*Youden's index=max (sensitivity+specificity-1).

†95\% Bootstrap Cl for the cut-off point associated with Youden's index.

$\ddagger$ Predictive value of a positive or negative result for the prevalence of smoking in the study group.

$\S$ Area under the receiver operating characteristic curve and $95 \% \mathrm{Cl}$.

${ }^{* *}$ Number of sources of exposure at work, home and elsewhere in leisure time.

SHS, second-hand smoking.

misreport in their smoking, as indicated by Dietz et $a l^{4}{ }^{4}$ In this study, exposure to SHS was associated with smoking. In other words, there were more smoking people around pregnant women who smoked. In addition, misclassification was significantly associated with exposure to SHS at home. Jhun et $a l^{14}$ and Orr et $a l^{25}$ also showed higher prevalence of smoking among pregnant women whose partners smoked at home. Having smoked previously was associated with a higher probability of misreporting the habit, as observed by England et al. ${ }^{13}$

This work showed an optimal cut-off point for discriminating pregnant women smokers from non-smokers of $82 \mathrm{ng} / \mathrm{ml}$, with a CI of 42 to $136 \mathrm{ng} / \mathrm{ml}$. Some studies proposed a cut-off of $50 \mathrm{ng} / \mathrm{ml},{ }^{13-16}$ coherent with the women not SHS exposed in this study. Other studies proposed cut-off points of $79 \mathrm{ng} / \mathrm{ml}^{18}$ and $85 \mathrm{ng} / \mathrm{ml}$, ${ }^{6}$ closer to the smoking dose and SHS exposure in our study sample. In our study population, both the prevalence of smoking and of SHS is high, and this can explain, in part, why our optimal cut-off point is higher than those reported in other studies. ${ }^{13-17}$ This is also supported by the fact that the optimal cut-off point decreased to $42 \mathrm{ng} / \mathrm{ml}(27-57)$ when the analysis was restricted to women who reported no SHS exposure and increased according to the number of sources reported. The validity of $27 \mathrm{ng} / \mathrm{ml}(11-43)$ as a cut-off point for differentiating occasional smokers from non-smokers was lower than that for differentiating daily smokers, and it could depend on SHS exposure and on the time spent from the last cigarette smoked, given the faster elimination of cotinine in pregnant women, ${ }^{10-12}$ information not collected in this study. There are no validation studies of cotinine in different biological matrices, blood (plasma or serum), saliva or urine, ${ }^{9} 16$ so it cannot be established which biomarker is the most reliable.

\section{Limitations of the study}

The current study has several limitations. From the eligible population, the participation rate was $56 \%$, and $85.6 \%$ of the women who agreed to participate completed the study. Therefore, the final study sample might not be fully representative of all pregnant women in the study areas, but its internal validity (absence of bias) is 
not necessarily affected. There were other likely sources of misclassification in addition to maternal misreporting of smoking status as misclassification of non-smokers as smokers because of the high degree of exposure to SHS. On the other hand, women who smoked occasionally but reported to be non-smokers might have low UC concentrations if they had not smoked recently, and their self-report and UC levels would be in agreement.

No information about last cigarette or last SHS exposure was obtained. We lost the opportunity of analysing this variable in the evolution of the UC, showing its influence in false negatives, above all, and especially relevant for occasional smokers.

Since the optimal cut-off point for UC is determined using self-reported smoking status as the gold standard, the validity of this assumption is important. On the one hand, it is unlikely that a non-smoking woman declared to be a smoker because a battery of items should be completed detailing smoking habits in this case. On the other hand, however, it is possible that some smokers did not reveal their habits. In order to minimise this type of bias, we excluded, in the additional analysis, selfreported non-smokers with implausibly high UC levels. In another sensitivity analysis, we excluded self-reported non-smokers who claimed to stop smoking during pregnancy, since these cases are at a higher risk of misclassification, as reported in table 3; the optimal cut-off point did not change after these exclusions. In general terms, the AUC shows a good overall accuracy, and we think that self-reported smoking is a reliable measure in this study. If some kind of misclassification occurs, it would lead to a shift towards the right in both distributions and a slight overestimation of the optimal cut-off point as a result.

One of the main strengths of this study was the possibility of assessing the role of baseline exposures to SHS in the estimate of cut-offs, given the detailed information collected on SHS exposure and its elevated prevalence. The confirmation that the cut-offs would differ according to the level of exposure to SHS emphasises the need of taking it into account, especially in countries with elevated SHS exposure.

\section{Implications for practice}

This study shows that the efforts made to encourage women to give up smoking before or during pregnancy are not sufficient or particularly effective, given that at least $18.5 \%$ of the pregnant women smoked in the third trimester. The results of this study indicate that the groups to which the most effort should be directed are young women, those of a European origin and those from a low social class. Further, the association observed in this study between active smoking of pregnant women and the presence of smokers in their close environment supports the hypothesis that this factor makes it more difficult to stop smoking. ${ }^{26}$ It is necessary to undertake effective programmes for reducing smoking before and during pregnancy, reaching also misclassified, and to reduce SHS exposure, in order to prevent risks for women and to the fetus.

\section{CONCLUSION}

Smoking is an important risk factor for health and development and should be taken into account as a confounder when analysing the potential effects of environmental contaminants in studies like the INMA project. Having a reliable marker like UC and a valid cut-off point that is able to discriminate regular or occasional smokers from nonsmokers are critical issues. The cut-off point of $82 \mathrm{ng} / \mathrm{ml}$ showed a good validity for discriminating smokers from non-smokers in our study sample, whereas $27 \mathrm{ng} / \mathrm{ml}$ is the optimal point for discriminating occasional smokers from non-smokers. It should be emphasised that cut-offs would differ based on baseline exposure to SHS, and this should be taken into account when selecting reference cut-offs for specific populations.

\section{Author affiliations}

${ }^{1}$ Public Health Department, Basque Government, San Sebastian, Spain

${ }^{2}$ University of Basque Country UPV/EHU, San Sebastian, Spain

${ }^{3}$ Health Research Institute (BIODONOSTIA), San Sebastian, Spain

${ }^{4}$ Spanish Consortium for Research on Epidemiology and Public Health (CIBERESP), Spain

${ }^{5}$ Center for Public Health Research (CSISP), Valencia, Spain

${ }^{6}$ Public Health Agency of Barcelona, Barcelona, Spain

${ }^{7}$ Institute of Biomedical Research (IIB Sant Pau), Barcelona, Spain

${ }^{8}$ Public Health Laboratory of Bilbao, Bilbao, Spain

${ }^{9}$ Center for Research in Environmental Epidemiology (CREAL), Barcelona, Spain

${ }^{10}$ Hospital del Mar Research Institute (IMIM), Barcelona, Spain

${ }^{11}$ Department of Preventive Medicine and Public Health, University of Oviedo, Oviedo, Spain

${ }^{12}$ Department of Nursing, University of Valencia, Valencia, Spain

Acknowledgements The authors are grateful to all fieldworkers for their assistance in administering the questionnaires. A full listing of the INMA project researchers can be found at http://www. proyectoinma.org/ presentacioninma/listado-investigadores/en_listado-investigadores.html.

Contributors JJA, MM and MR designed the study and analysed the data. $A M C$ and ME analysed cotinine in urine samples. MJL, AMC, LSM, MG, AF-S, $\mathrm{ME}, \mathrm{AL}, \mathrm{AT}$ and $\mathrm{FB}$ revised the design of the study and the results. JJA wrote the manuscript and the other authors participated in reviews of the different drafts and approved the final version.

Funding The INMA project is funded by grants from Instituto de Salud Carlos III (Red INMA G03/176 and CB06/02/0041) and Fundación Roger Torné. The studies in the specific regions were funded by the Spanish Ministry of Health (FIS 03/1615, 04/1436, 04/1509, 04/1112, 04/1931, 05/1079, 05/1052, 06/ 0867,06/1213, 07/0314, 08/1151, 09/02647, 04/2018, 09/02311), the Generalitat de Catalunya (CIRIT 1999SGR00241), the Diputación Foral de Gipuzkoa (DFG06/004), the Department of Health of the Basque Government (2005111093), the Regional Government of Andalucía (SAS 07/183), Obra social Cajastur, University of Oviedo and the Conselleria de Sanitat Generalitat Valenciana. http://www. proyectoinma.org/instituciones-participantes/ en_entidades-colaboradoras/.

\section{Patient consent Obtained.}

Ethics approval This study was conducted with the approval for each of the four cohorts and the hospital ethics committee of each centre.

Provenance and peer review Not commissioned; externally peer reviewed. 


\section{REFERENCES}

1. Murin S, Rafii R, Bilello K. Smoking and smoking cessation in pregnancy. Clin Chest Med 2011;32:75-91.

2. Bardy $A H$, Seppälä T, Lillsunde $P$, et al. Objectively measured tobacco exposure during pregnancy: neonatal effects and relation to maternal smoking. Br J Obstet Gynaecol 1993;100:721-6.

3. Burstyn I, Kapur N, Shalapay C, et al. Evaluation of the accuracy of self-reported smoking in pregnancy when the biomarker level in an active smoker is uncertain. Nicotine Tob Res 2009;11:670-8.

4. Dietz PM, Homa D, England LJ, et al. Estimates of nondisclosure of cigarette smoking among pregnant and nonpregnant women of reproductive age in the United States. Am J Epidemiol 2011;173:355-9.

5. Ford RPK, Tappin DM, Schluter PJ, et al. Smoking during pregnancy: how reliable are lof maternal self reports in New Zealand? J Epidemiol Community Health 1997;51:246-51.

6. Kendrick JS, Zahniser SC, Miller N, et al. Integrating smoking cessation into routine public prenatal care: The smoking cessation in pregnancy project. Am J Public Health 1995;85:217-22.

7. Lindqvist R, Lendahls L, Tollbom Ö, et al. Smoking during pregnancy: comparison of self-reports and cotinine levels in 496 women. Acta Obstet Gynecol Scand 2002;81:240-4.

8. Walsh RA, Redman S, Adamson L. The accuracy of self-report of smoking status in pregnant women. Addict Behav 1996;21:675-9.

9. Gorber SC, Schofield-Hurwitz S, Hardt J, et al. The accuracy of self-reported smoking: a systematic review of the relationship between self-reported and cotinine-assessed smoking status. Nicotine Tob Res 2009;11:12-24.

10. Benowitz NL. Cotinine as a biomarker of environmental tobacco smoke exposure. Epidemiol Rev 1996;18:188-203.

11. Rebagliato M, Bolúmar F, Florey CV, et al. Variations in cotinine levels in smokers during and after pregnancy. Am J Obstet Gynecol 1998;178:568-71.

12. Dempsey D, Jacob P, Benowitz NL. Accelerated metabolism of nicotine and cotinine in pregnant smokers. J Pharmacol Exp Ther 2002;301:594-8.

13. England LJ, Grauman A, Qian C, et al. Misclassification of maternal smoking status and its effects on an epidemiologic study of pregnancy outcomes. Nicotine Tob Res 2007;9:1005-13.
14. Jhun HJ, Seo HG, Lee DH, et al. Self-reported smoking and urinary cotinine levels among pregnant women in Korea and factors associated with smoking during pregnancy. J Korean Med Sci 2010;25:752-7.

15. Pickett KE, Rathouz PJ, Kasza K, et al. Self-reported smoking, cotinine levels, and patterns of smoking in pregnancy. Paediatr Perinat Epidemiol 2005;19:368-76.

16. SRNT Subcommittee on Biochemical Verification. Biochemical verification of tobacco use and cessation. Nicotine Tob Res 2002;4:149-59.

17. Higgins ST, Heil SH, Badger GJ, et al. Biochemical verification of smoking status in pregnant and recently postpartum women. Exp Clin Psychopharmacol 2007;15:58-66.

18. Spierto FW, Hannon WH, Kendrick JS, et al. Urinary cotinine levels in women enrolled in a smoking cessation study during and after pregnancy. J Smoking Relat Dis 1994;5:65-76.

19. Guxens M, Ballester F, Espada M, et al. Cohort profile: the INMAINfancia y Medio Ambiente-(Environment and Childhood) Project. Int $J$ Epidemiol 2011;41:930-40.

20. Domingo-Salvany A, Regidor E, Alonso J, et al. Proposal for a socia class measure. Working Group of the Spanish Society of Epidemiology and the Spanish Society of Family and Community Medicine [Spanish]. Aten Primaria 2000;25:350-63.

21. Zou KH, O'Malley AJ, Mauri L. Receiver-operating characteristic analysis for evaluating diagnostic tests and predictive models. Circulation 2007;115:654-7.

22. Perkins NJ, Schisterman EF. The inconsistency of 'optimal' cutpoints obtained using two criteria based on the receiver operating characteristic curve. Am J Epidemiol 2006;163:670-5.

23. Carpenter J, Bithell J. Bootstrap confidence intervals: when, which, what? A practical guide for medical statisticians. Stat Med 2000;19:1141-64.

24. Leader A, Fernández-Somoano A, López-Cima MF, et al. Educational inequalities in quantity, duration and type of tobacco consumption among lung cancer patients in Asturias: epidemiological analyses. Psicothema 2010;22:634-40.

25. Orr ST, Newton E, Tarwater PM, et al. Factors associated with prenatal smoking among black women in eastern North Carolina Matern Child Health J 2005;9:245-52.

26. Eiden RD, Molnar DS, Leonard KE, et al. Sources and frequency of secondhand smoke exposure during pregnancy. Nicotine Tob Res 2011;13:653-60. 